\title{
Pathway to Vinyl Chloride Production via Dehydrochlorination of 1,2-Dichloroethane in Ionic Liquid Media
}

\author{
Tom Boudewijns, ${ }^{\dagger}$ Marco Piccinini, ${ }^{\ddagger}$ Paul Degraeve, ${ }^{\ddagger}$ Armin Liebens, ${ }^{\ddagger}$ and Dirk De Vos ${ }^{* \dagger}$ \\ ${ }^{\dagger}$ Centre for Surface Chemistry and Catalysis, Department Molecular and Microbiological Systems, KU Leuven, 3000 Leuven, Belgium \\ ${ }^{\ddagger}$ Solvay SA, Rue de Ransbeek 310, 1120 Brussels, Belgium
}

\section{Supporting Information}

ABSTRACT: We present a novel approach to the dehydrochlorination of 1,2-dichloroethane using ionic liquid catalysts. After screening a wide range of ionic liquids, tetraalkylphosphonium chlorides show the best results, with much higher conversions compared with those of the current industrial "pyrolysis" process. This breakthrough approach has the remarkable advantage of operating at lower temperature while maintaining an excellent selectivity. This method shows high potential as a greener alternative for the current industrial process.

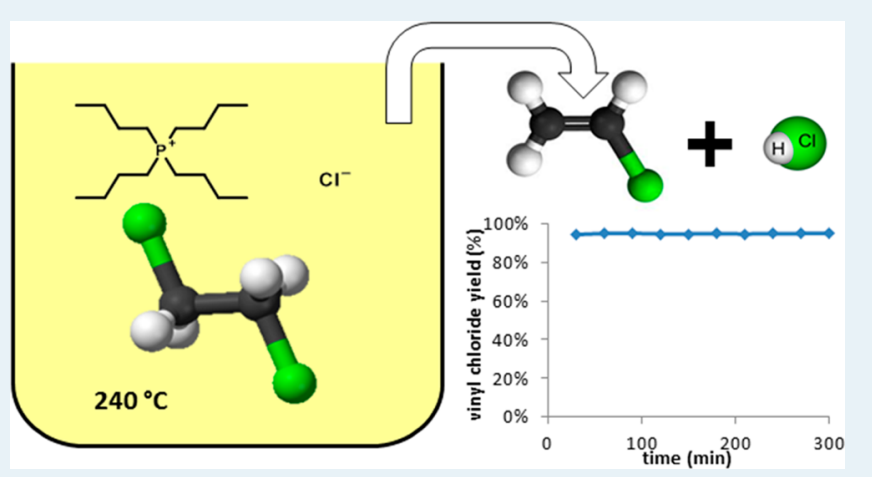

KEYWORDS: ionic liquids, quaternary phosphonium, dehydrochlorination, vinyl chloride, anion basicity

$\mathrm{D}$ ehydrochlorination of 1,2-dichloroethane (1,2-DCE) toward vinyl chloride monomer (VCM) is a paramount process step in the production of PVC. Current industrial processes utilize high temperature pyrolysis for cracking 1,2DCE into $\mathrm{VCM}$ and $\mathrm{HCl}^{1}$ however, this process is characterized by some important drawbacks: on one hand, 1,2-DCE conversion is limited at low temperature, but on the other hand, increasing the temperature leads to byproducts and coke formation $^{2-4}$ so that in practice, an optimal temperature of about $500-550{ }^{\circ} \mathrm{C}$ is used industrially. ${ }^{5}$ Under these conditions, conversions of 50-60\% and selectivities of $95-99 \%$ are obtained. The process is energy-intensive because of the high thermal input and low conversions that require important recycles. ${ }^{6,7}$ No suitable alternative for this process has been found so far, despite reports of activity of some heterogeneous catalysts, such as metal oxides with Lewis or Brønsted acid sites ${ }^{8}$ and poly(acrylonitrile)-based active carbon fibers with pyridinic basic sites. ${ }^{9}$ Initially, both systems show comparable conversion rates as the pyrolysis process but at lower temperatures; however, fast deactivation is observed because of blockage of the active sites by coke formation. This is explained by diffusion problems in the removal of reaction products, and as a result, side reactions lead to formation of carbonized products that block the catalytic sites.

To overcome this problem, we here propose a new group of catalysts that enable the fast removal of products to obtain high selectivity. The new catalysts are ionic liquids, which exhibit beneficial properties such as very low vapor pressure, a broad liquid range, and high thermal stability. Moreover, ionic liquids have shown a broad range of applications in catalysis. ${ }^{10}$ Initial reports on dehydrochlorination in ionic liquids have focused on the end-of-life treatment of poly(vinyl chloride). ${ }^{11-13}$ Although these reactions have been performed in batch and generally lead to poorly defined products, it is desirable to perform the dehydrochlorination of 1,2-DCE in a continuous mode and to maximize the VCM yield. For this, the negligible vapor pressure of ionic liquids is a huge advantage because this should prevent the loss of ionic liquid from the reactor while in principle allowing fast evacuation of the VCM and $\mathrm{HCl}$ products. We here demonstrate that with a tetraalkylphosphonium chloride, 1,2-DCE can be converted at 95\% to VCM, with $a>99.6 \%$ selectivity and with a stable activity over $60 \mathrm{~h}$ and more. Moreover, high VCM productivities (up to $0.6 \mathrm{~g} \mathrm{VCM} \mathrm{g}^{-1} \mathrm{IL}$ $\mathrm{h}^{-1}$ ) can be achieved with the best ionic liquid systems.

Reactions were conducted with a series of ionic liquids in an on-purpose-designed continuous setup. A dry nitrogen flow loaded with 1,2-DCE is continuously bubbled through a reactor vessel, which contains the well-stirred, thermostated ionic liquid (Figure 1). The outlet flow is then analyzed by online GC. Further details of the experimental setup are given in the Supporting Information (Figure S1). Because a large amount of $\mathrm{HCl}$ is formed during the reaction, the ionic liquid anion choice is limited. An anion derived from a weak acid such as acetate will bind the proton eliminated from 1,2-DCE and thus be removed as volatile acetic acid, while the ionic liquid is transformed to a chloride ionic liquid. More suitable anions would be tosylate; methyl sulfate; bistriflimide; and obviously, chloride. In the last case, no net anion exchange of the ionic

Received: April 8, 2015

Revised: May 27, 2015

Published: June 2, 2015 


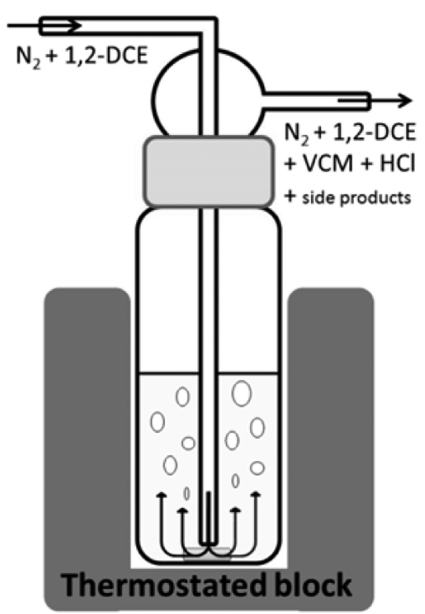

Figure 1. Scheme of the lab scale setup for dehydrochlorination of 1,2DCE with ionic liquids: a reactor placed in a thermostated block through which a nitrogen stream saturated with 1,2-DCE is bubbled.

liquid can occur. The cation choice is less limited, provided that the ionic liquid is thermally and chemically stable in the chosen reaction conditions. In the screening tests, $6 \mathrm{mmol}$ of ionic liquid is heated until $180{ }^{\circ} \mathrm{C}$ while 1,2 -DCE is fed at a rate of $1.4 \mathrm{mmol} / \mathrm{h}$ as a $\mathrm{N}_{2}$ gas flow containing $5 \mathrm{~mol} \%$ of 1,2-DCE.

Encouraging results were obtained with tetraalkylphosphonium chlorides, such as trihexyltetradecylphosphonium chloride $\left(\mathrm{C}_{666,14} \mathrm{P}^{+} \mathrm{Cl}^{-}\right)$, tributyltetradecylphosphonium chloride $\left(\mathrm{C}_{444,14} \mathrm{P}^{+} \mathrm{Cl}^{-}\right)$, and tetrabutylphosphonium chloride $\left(\mathrm{C}_{4444} \mathrm{P}^{+} \mathrm{Cl}^{-}\right)$, which are all commercially available. With these ionic liquids, the $1,2-\mathrm{DCE}$ conversions at $180{ }^{\circ} \mathrm{C}$ amount to $4 \%, 14 \%$, and $16 \%$, respectively. Remarkably, VCM is the only detectable product, demonstrating the high selectivity of the reaction and the adequate thermal stability of the ionic liquids (Table 1). This is not the case when alternative anions are used.

Table 1. Screening Reactions with Tetraalkylphosphonium Chlorides

$\begin{array}{lcc}\text { ionic liquid } & \text { VCM yield, } \%^{a} & \text { decomposition } \\ \mathrm{C}_{666,14} \mathrm{P}^{+} \mathrm{Cl}^{-} & 4 & \text { no } \\ \mathrm{C}_{444,14} \mathrm{P}^{+} \mathrm{Cl}^{-} & 14 & \text { no } \\ \mathrm{C}_{4444} \mathrm{P}^{+} \mathrm{Cl}^{-} & 16 & \text { no }\end{array}$

${ }^{a}$ Reaction temperature $180{ }^{\circ} \mathrm{C}, 6 \mathrm{mmol}$ of ionic liquid, and a feeding rate of $1.4 \mathrm{mmol}_{1,2-\mathrm{DCE} \mathrm{h}}^{-1}$ in $\mathrm{N}_{2}$.

For experiments with tetrabutylphosphonium bromide, tributylethylphosphonium diethyl phosphate or triisobutylmethylphosphonium tosylate, extra product peaks appear in the GC chromatogram. This points to the exchange of the anions under the given circumstances. Using the bromide ionic liquid, for instance, vinyl bromide, 1-chloro-2-bromoethane, and 1,2dibromoethane are formed; on the other hand, with, for example, the diethyl phosphate ionic liquid, volatile diethyl phosphoric acid is lost. This proves that chloride is most suitable as the anion in this dehydrochlorination reaction.

Because most promising conversions were obtained with alkyltributylphosphonium chlorides, only these ionic liquids were used in the further research. First, the temperature for the endothermic dehydrochlorination reaction was gradually raised using $\mathrm{C}_{4444} \mathrm{P}^{+} \mathrm{Cl}^{-}$to increase conversion and better evaluate selectivity and thermal stability. At $240{ }^{\circ} \mathrm{C}$, a maximum conversion of $63 \%$ was reached (Figure 2a). Surprisingly, very high selectivities are still obtained at such higher temperatures. At $200{ }^{\circ} \mathrm{C}$, no side products at all are observed in the outlet stream, whereas at 220 and $240{ }^{\circ} \mathrm{C}$, small fractions of 1,1 dichloroethane $\left(<0.08 \%\right.$ at $\left.240{ }^{\circ} \mathrm{C}\right)$ and acetylene $(<0.02 \%$ at $240{ }^{\circ} \mathrm{C}$ ) are detected. These are formed by rehydrochlorination and further dehydrochlorination of VCM, respectively. Despite these side reactions, the selectivity remains above $99.9 \%$, and the ionic liquid remains thermally stable (Figure $2 \mathrm{~b}$ ).

Taking into account the promising results obtained with $\mathrm{C}_{4444} \mathrm{P}^{+} \mathrm{Cl}^{-}$, an optimal activity in phosphonium chlorides was searched by varying the side chain length and structure. Because the ionic centers are believed to be the active sites, tetramethylphosphonium chloride $\left(\mathrm{C}_{1111} \mathrm{P}^{+} \mathrm{Cl}^{-}\right)$was added to $\mathrm{C}_{4444} \mathrm{P}^{+} \mathrm{Cl}^{-}$to increase the volumetric density of ionic centers. Use of a mixture of $75 \% \mathrm{C}_{4444} \mathrm{P}^{+} \mathrm{Cl}^{-}$and $25 \% \mathrm{C}_{1111} \mathrm{P}^{+} \mathrm{Cl}^{-}$, at $240{ }^{\circ} \mathrm{C}$, however, results in a drop in conversion to $30 \%$ for the mixture, compared with $63 \%$ for pure $\mathrm{C}_{4444} \mathrm{P}^{+} \mathrm{Cl}^{-}$.

To scan the effect of alkyl chain length, different alkyltributylphosphonium chlorides $\left(\mathrm{C}_{444 \mathrm{n}} \mathrm{P}^{+} \mathrm{Cl}^{-}\right)$were synthesized. For these syntheses, in the present work, a closed Teflonlined autoclave was preferred to the reflux setup described in the literature reference. ${ }^{14}$ This approach makes it easier to keep the volatile alkyl chlorides confined under autogenous pressure. This allows synthesizing high-purity ionic liquids after drying on a Schlenk line, as confirmed by ${ }^{1} \mathrm{H}$ NMR quantification. Together with some commercial $\mathrm{C}_{444 \mathrm{n}} \mathrm{P}^{+} \mathrm{Cl}^{-}$compounds, the synthesized $\mathrm{C}_{444 \mathrm{n}} \mathrm{P}^{+} \mathrm{Cl}^{-}$were tested at $240{ }^{\circ} \mathrm{C}$ with $6 \mathrm{mmol}$ of IL and a 1,2-DCE feeding rate of $1.4 \mathrm{mmol} \mathrm{h}^{-1}$. The results (Figure 3a) show an optimum in conversion of $63 \%$ for the symmetric $\mathrm{C}_{4444} \mathrm{P}^{+} \mathrm{Cl}^{-}$. All ionic liquids with one longer alkyl chain show a lower but constant conversion of around 50\%, indicating that a further increase in the alkyl chain length does not influence conversion. The effect of a shorter chain substitution is more pronounced, as can be seen for $\mathrm{C}_{4441} \mathrm{P}^{+} \mathrm{Cl}^{-}$: the conversion drops to $28 \%$, which is similar to what is obtained with the $25-75 \%$ mixture of $\mathrm{C}_{1111} \mathrm{P}^{+} \mathrm{Cl}^{-}$and $\mathrm{C}_{4444} \mathrm{P}^{+} \mathrm{Cl}^{-}$. The shorter methyl chains allow for a closer approach of the chloride anion to the phosphonium center, resulting in a stronger electrostatic bonding of the chloride and, thus, a decreased basicity of the chloride anions. ${ }^{14,15}$ This suggests that a key parameter for the ionic liquid is the distance of closest approach between the cationic center and the anion. Because the conversion obtained with $\mathrm{C}_{4443} \mathrm{P}^{+} \mathrm{Cl}^{-}$is only a little lower than that with $\mathrm{C}_{4444} \mathrm{P}^{+} \mathrm{Cl}^{-}$, additional ionic liquids were synthesized starting from tripropylphosphine. Both $\mathrm{C}_{3333} \mathrm{P}^{+} \mathrm{Cl}^{-}$ and $\mathrm{C}_{3338} \mathrm{P}^{+} \mathrm{Cl}^{-}$give a conversion of $55 \%$ at $240{ }^{\circ} \mathrm{C}$ under standard conditions. So far, $\mathrm{C}_{4444} \mathrm{P}^{+} \mathrm{Cl}^{-}$appears to be the best candidate.

To study the effect of nonlinear side chains, other phosphonium salts were synthesized and tested. The effect of branched alkyl chains was studied with phosphonium salts synthesized from triisobutylphosphine, and tricyclohexylphosphine was used to examine the effect of cyclic substituents. Both syntheses were carried out with 1-chlorobutane, yielding butyltriisobutylphosphonium chloride $\left(\mathrm{C}_{i 4 i 4 i 44} \mathrm{P}^{+} \mathrm{Cl}^{-}\right)$, and butyltricyclohexylphosphonium chloride $\left(\mathrm{C}_{c 6 c 6 c 64} \mathrm{P}^{+} \mathrm{Cl}^{-}\right)$. To study aromatic side chains, the Wittig reagent methyltriphenylphosphonium chloride $\left(\mathrm{Ph}_{3} \mathrm{C}_{1} \mathrm{P}^{+} \mathrm{Cl}^{-}\right)$was used. This compound has a melting point of $220{ }^{\circ} \mathrm{C}$ and thus can be tested in the liquid state at $240{ }^{\circ} \mathrm{C}$. A low conversion of only $12 \%$ is obtained with the phenyl-substituted phosphonium center. With the cyclohexyl substituents, the conversion amounts to only $36 \%$ (Figure $3 \mathrm{~b}$ ). The bulky cyclic groups 


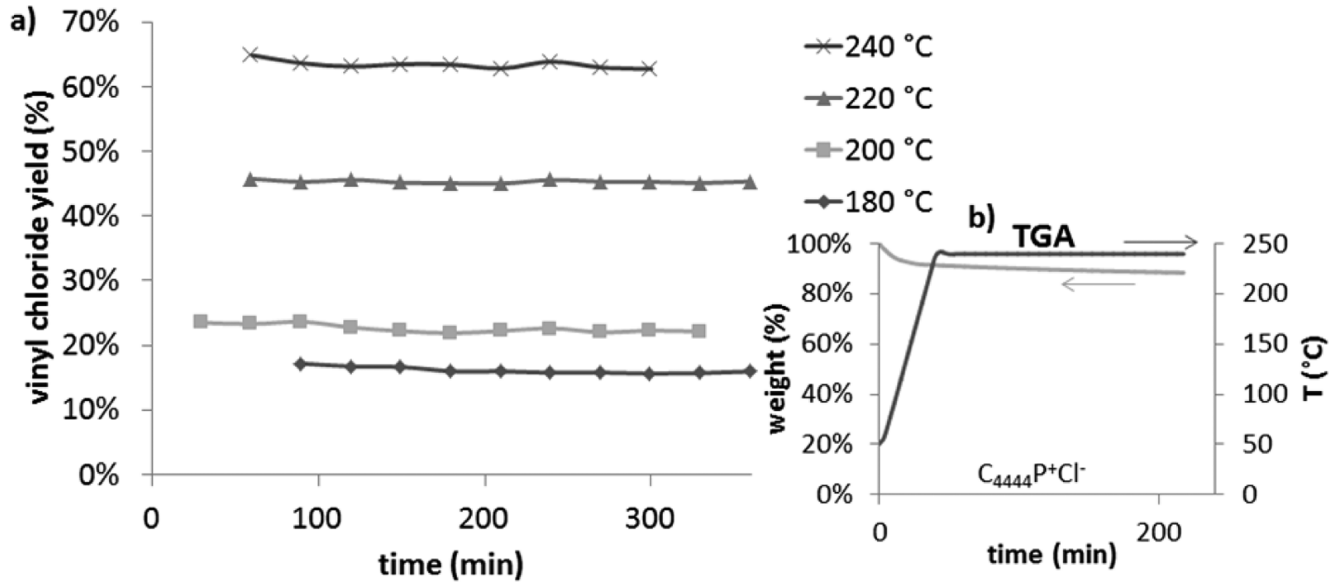

Figure 2. Effect of temperature on 1,2-DCE dehydrochlorination using $\mathrm{C}_{4444} \mathrm{P}^{+} \mathrm{Cl}^{-}$: (a) VCM yield (\%) as a function of time-on-stream. Reaction parameters: $6 \mathrm{mmol}$ of $\mathrm{C}_{4444} \mathrm{P}^{+} \mathrm{Cl}^{-}$, feeding rate of $1.4 \mathrm{mmol} 1,2-\mathrm{DCE} \mathrm{h}{ }^{-1}$ in $\mathrm{N}_{2}$. (b) Thermogravimetric analysis of $\mathrm{C}_{4444} \mathrm{P}^{+} \mathrm{Cl}^{-}$: initial temperature ramp of $5{ }^{\circ} \mathrm{C} / \mathrm{min}$ to $240^{\circ} \mathrm{C}$, where the temperature is kept constant for $3 \mathrm{~h}$.
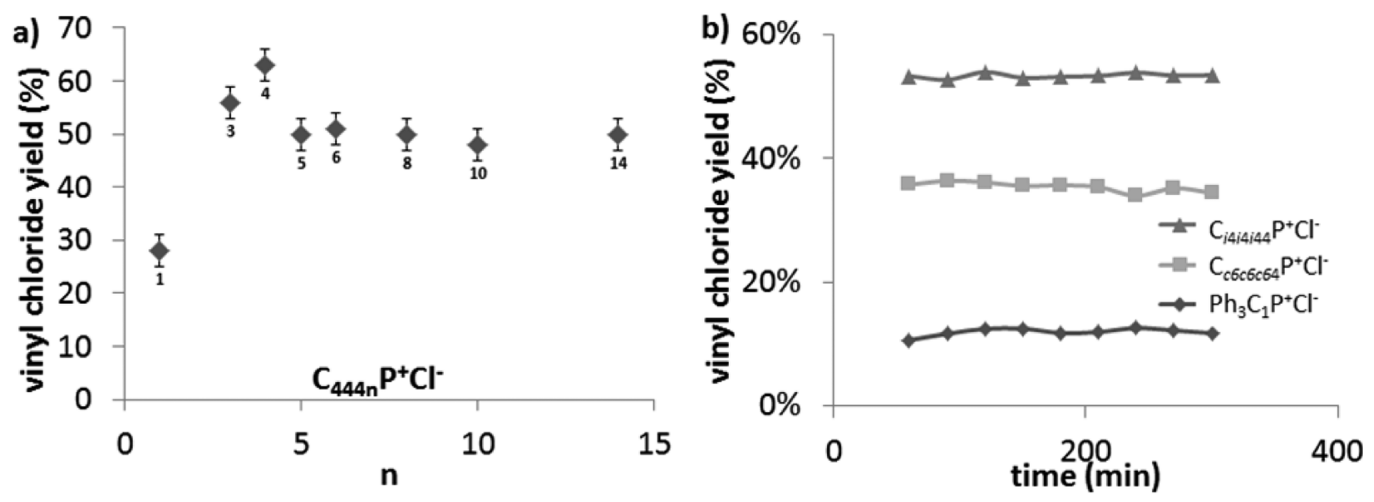

Figure 3. Effect of side chain length and structure on the activity of different quaternary phosphonium chlorides. (a) Steady-state VCM yield (\%) for reactions at $240{ }^{\circ} \mathrm{C}$ with alkyltributylphosphonium chlorides in which the carbon number $(n)$ of one alkyl chain is varied. (b) VCM yield (\%) as a function of time for reactions at $240{ }^{\circ} \mathrm{C}$ with butyltriisobutylphosphonium chloride $\left(\mathrm{C}_{i 4 i 4 i 44} \mathrm{P}^{+} \mathrm{Cl}^{-}\right)$, butyltricyclohexylphosphonium chloride $\left(\mathrm{C}_{c 6 c 6 c 64} \mathrm{P}^{+} \mathrm{Cl}^{-}\right)$, and methyltriphenylphosphonium chloride $\left(\mathrm{Ph}_{3} \mathrm{C}_{1} \mathrm{P}^{+} \mathrm{Cl}^{-}\right)$.

seem to impede too strongly the access to the phosphonium cation, making it less available for ion pairing with the chloride that is leaving from the 1,2-DCE reactant. This also explains the lower conversion obtained with $\mathrm{C}_{666,14} \mathrm{P}^{+} \mathrm{Cl}^{-}$in the screening (Table 1) because of the increased shielding of the cation due to the longer alkyl chains. Finally, results obtained with the isobutyl groups are comparable to those with linear chains with, for instance, a conversion of 52\% using butyltriisobutylphosphonium chloride.

The results suggest that there is a subtle relationship between the activity of the ionic liquid catalyst and the accessibility of the phosphonium cation or the strength of the interaction between the cation and anion. It has been well proven that the basicity of an anion in an ionic liquid is much enhanced compared with that of anions in molecular solvents or fully inorganic salts, as evidenced, for instance, by catalytic results for classical base-catalyzed reactions. ${ }^{16,17}$ By calculating the most negative surface electrostatic potential for $\mathrm{NaCl}$ and 1-butyl-3methylimidazolium chloride, it was found that the enhanced basicity of $\mathrm{Cl}^{-}$in the ionic liquid is directly related to the larger (average) anion-cation distance. ${ }^{18}$

In comparing phosphonium to $\mathrm{N}$-containing ionic liquids, it appears that the more dispersed distribution of the positive charge in $\mathrm{C}_{4444} \mathrm{P}^{+}$than in imidazolium or quaternary ammonium cations leads to a weaker electrostatic interaction between cation and anion and, therefore, an enhanced basicity of the anion. ${ }^{15,19,20}$ Thus, in the 1,2-DCE dehydrochlorination, the chloride anions of the ionic liquid can be expected to act as bases in a E2 type elimination and abstract a proton from 1,2DCE, with almost simultaneous elimination of a chloride leaving group. This would explain the generally observed superiority of phosphonium ILs in comparison with all other chloride ILs containing N-based cations.

The superior thermal stability of the phosphonium cations in comparison with, for instance, ammonium cations obviously is a major asset, as well. ${ }^{21}$ Although the quaternary ammonium chlorides are generally decomposed at temperatures above 200 ${ }^{\circ} \mathrm{C}$ in our setup, $\mathrm{C}_{4444} \mathrm{P}^{+} \mathrm{Cl}^{-}$shows stable conversion at $240{ }^{\circ} \mathrm{C}$ for more than $60 \mathrm{~h}$. However, during reaction, very small butene fractions are detected in the outlet stream. Some dealkylation will thus occur at $240{ }^{\circ} \mathrm{C}$, but over $60 \mathrm{~h},<1 \%$ of the phosphonium centers will lose an alkyl group, without any perceptible influence on the 1,2-DCE conversion. Because in thermal decomposition of phosphonium chlorides, phosphines and chloroalkanes are formed, the phosphines can react again to phosphonium chlorides. ${ }^{14,22}$ In such a reaction, 1,2-DCE could also be used to alkylate the phosphine with a 2chloroethyl group; however, after more than $60 \mathrm{~h}$ of reaction, these changes in ionic liquid are undetectable with ${ }^{1} \mathrm{H} \mathrm{NMR}$, 
thus underlining the thermal stability of phosphonium chlorides under these conditions (Figure S3).

Another advantage of $\mathrm{C}_{4444} \mathrm{P}^{+} \mathrm{Cl}^{-}$is the appropriate, optimal distance of closest approach between cation and anion. A too close approach between the chloride and phosphonium cations with one or more methyl chains is expected to decrease the basicity of chloride and effectively results in systematically inferior conversions (Figures 2a, 3a). On the other hand, increasing the length of the alkyl chains could improve the solubility of the 1,2-DCE reactant in the ionic liquid at the relevant, high reaction temperatures. Because no improvement of the activity is monitored for chain lengths beyond $n=4$, it seems that $\mathrm{C}_{4444} \mathrm{P}^{+} \mathrm{Cl}^{-}$dissolves a sufficient concentration of 1,2-DCE to maximize the reaction rate. Remarkably, substitution of the phosphonium centers with too long or bulky substituents decreases the reactivity again, as seen for trihexyltetradecylphosphonium or butyltricyclohexylphosphonium compounds. This indicates that the phosphonium cation has a role to play in ion pairing with the chloride leaving group in the $\mathrm{E} 2$ mechanism.

Attempts to increase the reaction rates by addition of a series of inorganic chlorides to $\mathrm{C}_{4444} \mathrm{P}^{+} \mathrm{Cl}^{-}$invariably resulted in lower rates; tested compounds include $\mathrm{FeCl}_{3}, \mathrm{LiCl}, \mathrm{CsCl}, \mathrm{BaCl}_{2}$, and $\mathrm{LaCl}_{3}$. The presence of inorganic cations will decrease the basicity of chloride anions as a result of a stronger interaction compared with the phosphonium-chloride interaction. Remarkably, in the presence of $\mathrm{PdCl}_{2}$, a significant acetylene formation was detected $\left(\sim 11 \%\right.$ selectivity at $\left.240{ }^{\circ} \mathrm{C}\right)$, proving that even in the presence of formed $\mathrm{HCl}$, acetylene can be evacuated from the $\mathrm{C}_{4444} \mathrm{P}^{+} \mathrm{Cl}^{-}$ionic liquid. However, with only $\mathrm{C}_{4444} \mathrm{P}^{+} \mathrm{Cl}^{-}$, the second dehydrohalogenation to acetylene occurs only to a negligible extent, as is expected for an E2 reaction with charged transition states. The very low reactivity of VCM in the ionic liquid without added metal salts is a crucial advantage for the selectivity of the process.

To increase the conversion levels, reactions were conducted with several reactors in series. By applying the same amount of ionic liquid divided over 3 reactors, conversion is increased to $75 \%$ at $240{ }^{\circ} \mathrm{C}$. By using 6 times the amount of ionic liquid in 4 reactors, a conversion of $93 \%$ can be obtained for over $60 \mathrm{~h}$ (Figure S4). In these cases, unreacted 1,2-DCE can be dehydrochlorinated in the next reactors, allowing for higher yields to be achieved. By optimizing the reactor design, this can possibly be further improved. Even at these high conversion levels, selectivity remains $>99.5 \%$. Alternatively, the productivity of the ionic liquid system was boosted by raising the inlet concentration, and eventually even dosing almost pure liquid 1,2-DCE to the hot ionic liquid (Figure S2). By systematically increasing the 1,2-DCE feeding rate from $1.4 \mathrm{mmol} \mathrm{h}^{-1}$ to 40 $\mathrm{mmol} \mathrm{h}{ }^{-1}$, which corresponds to a 87 vol \% feed gas mixture, conversion stabilized at $50 \%$ with $>99.6 \%$ selectivity. Productivity, however, gradually increased from $<0.03 \mathrm{~g}$ $\mathrm{VCM} /(\mathrm{g} \mathrm{IL} \mathrm{h})^{-1}$ to over $0.6 \mathrm{~g} \mathrm{VCM} /(\mathrm{g} \mathrm{IL} \mathrm{h})^{-1}$. By placing two reactors in series and thereby doubling the amount of ionic liquid, conversion was increased to $70 \%$ at a feeding rate of 26 mmol $\mathrm{h}^{-1}$. The higher productivities, together with the satisfactory thermal and chemical stability, support the possible applicability of this process in industry.

Summarizing, phosphonium chloride ionic liquids are unique solvents and catalysts for vapor phase dehydrohalogenations. The enhanced basicity of the chloride allows the reaction to proceed via an E2 mechanism, at difference with the industrially practiced radical chain process. The high thermal stability and negligible vapor pressure of e.g. $\mathrm{C}_{4444} \mathrm{P}^{+} \mathrm{Cl}^{-}$allow for quick evacuation not only of vinyl chloride but also of $\mathrm{HCl}$ in the continuous reaction setup, thus continuously regenerating the chloride base in the reaction solvent. In comparison with the pyrolytic process, side reactions are negligible, especially at high conversions. Significant insight has been acquired in the relation between phosphonium cation structure and reaction rate. Finally, high productivities can be achieved by direct injection of liquid 1,2-dichloroethane.

\section{ASSOCIATED CONTENT}

\section{S Supporting Information}

The Supporting Information is available free of charge on the ACS Publications website at DOI: 10.1021/acscatal.5b00736.

Experimental details and illustrations (PDF)

\section{AUTHOR INFORMATION}

\section{Corresponding Author}

*E-mail: dirk.devos@biw.kuleuven.be.

\section{Notes}

The authors declare no competing financial interest.

\section{ACKNOWLEDGMENTS}

This study was generously supported by Solvay (Belgium). The work of D. De Vos is supported by funding from FWO, KULeuven, and IWT.

\section{REFERENCES}

(1) Dreher, E.-L.; Beutel, K. K.; Myers, J. D.; Lübbe, T.; Krieger, S.; Pottenger, L. H. Chloroethanes and Chloroethylenes. Ullmann's Encyclopedia of Industrial Chemistry; Wiley-VCH: Weinheim, 2014; pp $1-81$.

(2) Li, C.; Hu, G.; Zhong, W.; He, W.; Du, W.; Qian, F. Ind. Eng. Chem. Res. 2013, 52, 17501-17516.

(3) Borsa, A. G.; Herring, A. M.; Mckinnon, J. T.; Mccormick, R. L.; Ko, G. H. Ind. Eng. Chem. Res. 2001, 40, 2428-2436.

(4) Huybrechts, G.; Wouters, G. Int. J. Chem. Kinet. 2002, 34, 316321

(5) Schirmeister, R.; Kahsnitz, J.; Träger, M. Ind. Eng. Chem. Res. 2009, 48, 2801-2809.

(6) Holbrook, K.; Walker, R.; Watson, W. J. Chem. Soc. B 1971, 577582.

(7) Salouhi, M. J. Chim. Phys. Phys.-Chim. Biol. 1999, 96, 797-809.

(8) Shalygin, A. S.; Koval, L. M.; Malysheva, L. V.; Kotsarenko, N. S.; Paukshtis, E. A. Chem. Sustain. Dev. 2009, 17, 417-422.

(9) Sotowa, C.; Watanabe, Y.; Yatsunami, S.; Korai, Y.; Mochida, I Appl. Catal., A 1999, 180, 317-323.

(10) Pârvulescu, V. I.; Hardacre, C. Chem. Rev. 2007, 107, 26152665.

(11) Glas, D.; Hulsbosch, J.; Dubois, P.; Binnemans, K.; De Vos, D. E. ChemSusChem 2014, 7, 610-617.

(12) Zhao, T.; Zhou, Q.; He, X.-L.; Wei, S.-D.; Wang, L.; van Kasteren, J. M. N.; Wang, Y-Z. Green Chem. 2010, 12, 1062.

(13) Zhao, T.; Zhou, Q.; Jiang, X.; Du, A.; Wang, Y. Int. Soc. Fluoride Res. 2009, 260-262.

(14) Adamová, G.; Gardas, R. L.; Nieuwenhuyzen, M.; Puga, A. V.; Rebelo, L. P. N.; Robertson, A. J.; Seddon, K. R. Dalton Trans. 2012, $41,8316-32$.

(15) Xu, D.; Yang, Q.; Su, B.; Bao, Z.; Ren, Q.; Xing, H. J. Phys. Chem. B 2014, 118, 1071-9.

(16) Fabris, M.; Lucchini, V.; Noè, M.; Perosa, A.; Selva, M. Chem. Eur. J. 2009, 15, 12273-12282.

(17) Lucchini, V.; Noè, M.; Selva, M.; Fabris, M.; Perosa. Chem. Commun. 2012, 48, 5178-80. 
(18) Yang, Q.; Xing, H.; Bao, Z.; Su, B.; Zhang, Z.; Yang, Y.; Dai, S.; Ren, Q. J. Phys. Chem. B 2014, 118, 3682-8.

(19) Blundell, R. K.; Licence, P. Phys. Chem. Chem. Phys. 2014, 16, $15278-88$.

(20) Carvalho, P. J.; Ventura, S. P. M.; Batista, M. L. S.; Schröder, B.; Gonçalves, F.; Esperança, J.; Mutelet, F.; Coutinho, J. A. P. J. Chem. Phys. 2014, 140, 064505.

(21) Tsunashima, K.; Niwa, E.; Kodama, S.; Sugiya, M.; Ono, Y. J. Phys. Chem. B 2009, 113, 15870-15874.

(22) Bradaric, C. J.; Downard, A.; Kennedy, C.; Robertson, A. J.; Zhou, Y. Green Chem. 2003, 5, 143-152. 